\title{
Reliability and validity of skin temperature measurement by telemetry thermistors and a thermal camera during exercise in the heat
}

\author{
CA James, AJ Richardson, PW Watt and NS Maxwell \\ Mr Carl James - Corresponding author: Exercise in Extreme Environments Research Group, \\ University of Brighton, Welkin House, Denton Road, Eastbourne. BN20 7SN, 01273643754. \\ C.James2@brighton.ac.uk
}

Dr Alan Richardson: A.J.Richardson@brighton.ac.uk

Dr Peter Watt: P.Watt@brighton.ac.uk

Dr Neil Maxwell: N.Maxwell@brighton.ac.uk

\begin{abstract}
New technologies afford convenient modalities for skin temperature $\left(\mathrm{T}_{\mathrm{SKIN}}\right)$ measurement, notably involving wireless telemetry and non-contact infrared thermometry. The purpose of this study was to investigate the validity and reliability of skin temperature measurements using a telemetry thermistor system (TT) and thermal camera (TC) during exercise in a hot environment. Each system was compared against a certified thermocouple, measuring the surface temperature of a metal block in a thermostatically controlled waterbath. Fourteen recreational athletes completed two incremental running tests, separated by one week. Skin temperatures were measured simultaneously with TT and TC compared against a hard-wired thermistor system (HW) throughout rest and exercise. Post hoc calibration based on waterbath results displayed good validity for TT (mean bias $[\mathrm{MB}]=-$ $0.18^{\circ} \mathrm{C}$, typical error $\left.[\mathrm{TE}]=0.18^{\circ} \mathrm{C}\right)$ and reliability $\left(\mathrm{MB}=-0.05^{\circ} \mathrm{C}, \mathrm{TE}=0.31^{\circ} \mathrm{C}\right)$ throughout rest and exercise. Poor validity $\left(\mathrm{MB}=-1.4^{\circ} \mathrm{C}, \mathrm{TE}=0.35^{\circ} \mathrm{C}\right)$ and reliability $\left(\mathrm{MB}=-0.65^{\circ} \mathrm{C}\right.$, $\mathrm{TE}=0.52^{\circ} \mathrm{C}$ ) was observed for $\mathrm{TC}$, suggesting it may be best suited to controlled, static situations. These findings indicate TT systems provide a convenient, valid and reliable alternative to HW, useful for measurements in the field where traditional methods may be impractical.
\end{abstract}

Key words; Reliability, Validity, skin temperature, thermal camera, heat stress, exercise. 


\section{Introduction}

Skin temperature $\left(\mathrm{T}_{\mathrm{SKIN}}\right)$ measurement has application for research (Harper-Smith et al. 2010), occupational health (Kim et al. 2013) and clinical monitoring (Sherman et al. 1996). It is through the skin that the body loses or gains heat and as such, $\mathrm{T}_{\text {SKIN }}$ plays an important role in human thermoregulation. $\mathrm{T}_{\mathrm{SKIN}}$ is a consequence of dermis microcirculation, which is mediated through activity of the sympathetic nervous system and regulated by the hypothalamus. Typically $\mathrm{T}_{\mathrm{SKIN}}$ may initially reduce during exercise as a consequence of sweat on the skin surface and blood shifting towards working skeletal muscles (Torii et al. 1992). However, a steady rise is observed during endurance exercise as core temperature $\left(\mathrm{T}_{\mathrm{CORE}}\right)$ increases, with elevated ambient temperatures increasing the rate of $\mathrm{T}_{\text {SKIN }}$ increase (Roberts \& Wenger 1979). Whilst $\mathrm{T}_{\text {SKIN }}$ may be interpreted in isolation, it also forms a component of derivative calculations of heat strain, such as body heat content (Jay \& Kenny 2007) and mean body temperature (Jay et al. 2007). Such calculations assist in understanding the mechanisms underpinning practical thermal interventions such as precooling and heat acclimation, by providing an objective measure of whole-body thermal dynamics.

Typically, $\mathrm{T}_{\text {SKIN }}$ has been measured using thermocouples or wired thermistors with recent literature adopting wired thermistors as the criterion measure when validating new tools (Kelechi et al. 2011, Buono et al. 2007, Burnham et al. 2006). A thermocouple is a temperature-measuring device consisting of two dissimilar conductors that contact each other at one or more joint locations. It produces a measureable electrical potential difference proportional to the temperature difference against another joint which is set at a reference temperature in another part of the circuit. Thermistors are resistors in which resistance varies with temperature, allowing stored calibration data within the circuit to convert this to a temperature. Such devices have been shown to be robust and accurate to $0.045^{\circ} \mathrm{C}$ across a range $\left(10-40^{\circ} \mathrm{C}\right)$ of waterbath temperatures (Harper-Smith et al. 2010). Thermistors and thermocouples are non-invasive, but the associated wiring requires familiarisation and a hardwired connection to a datalogger, making field testing problematic. This in turn, limits the external validity of thermal interventions which are untested in the field.

Recent developments in wireless thermometry provides an alternative to hard-wired systems, particularly as some telemetry devices appear more accurate than wired thermistors (HarperSmith et al. 2010), require little familiarisation and provide freedom of movement for the 
person being measured. Harper-Smith et al. (2010) examined wireless iButtons (Maxim Integrated Products Inc. California, USA) in a waterbath as well as on human skin during exercise in hot conditions. Typical error was $<0.3^{\circ} \mathrm{C}$, Pearson and Intra-class correlation (ICC) coefficients $>0.9$ and coefficient of variation (CV) $<1 \%$ when compared against wired thermistors which were the criterion measure during exercise. The size and convenience of iButtons undoubtedly affords opportunities for measurements in novel environments, however the lack of real-time data may preclude their use in safety monitoring and research environments. Dermal temperature patches for physiological monitoring systems are wireless and offer live data, but being single-use only, carry significant purchase and consumable costs, which may prohibit use for large sample sizes. Consequently, a newly-developed telemetry system, whereby thermistors are connected to a transmitter worn on the person, may offer the benefits of live data without long, trailing connecting wires or being restricted to the laboratory.

Infrared thermometry is another technique that is used in research (Costello et al. 2012) and clinical environments (Ring \& Ammer 2012) where $T_{\text {SKIN }}$ is an important variable to measure. Thermal cameras receive and process infrared radiation emitted from a surface, using this information to display the production and dissipation of heat. The ability of a surface to emit energy by radiation is termed 'emissivity' and allows the temperature of the emitting surface to be calculated. Thermopiles or microbolometers within the cameras absorb this infrared radiation, eliciting a change in electrical resistance that a colour palette can use to display temperatures of an object. Handheld infrared thermometers provide temperature at specific points based on the same principle and are widely used for measuring core temperature via the tympanic membrane and increasingly for $\mathrm{T}_{\text {SKIN }}$ (Ring \& Ammer 2012). Measurements from such devices demonstrate strong association with wired thermistors, providing valid measures of mean $\mathrm{T}_{\text {SKIN }}$ at rest $(r=0.95)$ and whilst walking in the heat $(r=0.98$, Buono et al. 2007). This technology appears reliable, with mean inter-examiner intraclass correlation of $r=0.88$ (range $0.73-0.99$ ) between $\mathrm{T}_{\mathrm{SKIN}}$ measurements on consecutive days (Zaproudina et al. 2008). The majority of literature utilising thermal cameras as a measure of $\mathrm{T}_{\text {SKIN }}$ has involved thermogram images taken at rest being retrospectively analysed using software to identify area average temperatures for specified regions of anatomical interest. Measuring temperature across a region of interest enhances construct validity by helping to avoid inter-individual variation of veins and vascularisation 
and the consequential non-uniform heat production, a potential confounding error when taking readings from a single spot on an image or from attached thermistors (Chudecka \& Lubkowska 2012). Broadly, this technique has been shown to be valid (correlation range $r=0.71-0.77$, Roy et al. 2006) and reliable (correlation range $r=0.82-0.97$, Selfe et al. 2006), such that it has been recommended for clinical use (Ng et al. 2004; Ring \& Ammer 2012). However, large errors versus a thermocouple during rest and exercise have also been reported $\left(-0.75^{\circ} \mathrm{C}\right.$, Fernandes et al. 2014), making it unclear within which situations it may have application. Recent developments in thermal camera technology permit high speed imaging, offering a real-time thermal image, such that cameras can produce whole images for post hoc analysis as well as instantaneous spot analysis. These improvements allow simultaneous comparison against other $\mathrm{T}_{\text {SKIN }}$ measures, facilitating an objective assessment of the potential of thermal cameras as a multi-purpose tool for environmental exercise physiology research.

To our knowledge, wired thermistors, telemetry thermistors and a thermal camera have not been compared simultaneously for live $\mathrm{T}_{\text {SKIN }}$ measurement during exercise in hot environments. Therefore, the aim of this study was to compare the reliability and validity of these measurement tools for live $\mathrm{T}_{\mathrm{SKIN}}$ measurement in athletes exercising in a hot and humid environment. We hypothesized that telemetry thermistors and a thermal camera would provide acceptable levels of error for both reliability and validity when compared against hard wired thermistors during exercise in the heat 


\section{Methods}

\subsection{Experimental design}

The study was organised into two parts; a waterbath comparison and human skin temperature measurement during exercise. Both parts of the study assessed validity and reliability of tools. During the waterbath analysis, data was collected for 20 minutes across seven stable temperatures within the range $25-40^{\circ} \mathrm{C}$. Stability was defined as a deviation of no more than $0.1^{\circ} \mathrm{C}$ measured by the criterion thermocouple over 5 min consecutively. Retest reliability was examined on the following day. In order to assess the measurement tools in a relevant context for endurance exercise in the heat, an incremental exercise test was completed on each athlete volunteer. Re-tests of $\mathrm{T}_{\text {SKIN }}$ measurements were separated by one week to prevent an acclimation effect (Barnett \& Maughan 1993) and taken at the same time of day (Winget 1985), with the second trial data used for validity analysis.

\subsection{Participants}

Fourteen male recreational club runners volunteered as participants (mean [SD]): age 38 (11) years, stature $179(8) \mathrm{cm}$, mass $77.3(7.1) \mathrm{kg}$, sum of skinfolds 33.6 (7.7) $\mathrm{mm}, \mathrm{V} \square 0_{2 \max } 57.3$ (4) $\mathrm{mL} \cdot \mathrm{kg}^{-1} \cdot \mathrm{min}^{-1}$. Each participant provided written informed consent and stated their recent medical history. Ethical approval was provided by the institutional ethics committee following the principles outlined by the Declaration of Helsinki of 1975, as revised in 2008. Participants were asked to replicate their diet in the 12 hours prior to each session and refrain from alcohol, caffeine and strenuous activity for 24 hours prior to the measurements as has been previously controlled in similar studies in the field (Harper-Smith et al. 2010).

\subsection{Measurement tools}

During the waterbath tests, measurements from all thermistors and the thermal camera (TC) were referenced against a multi-point calibrated and certified thermocouple (Type K probe attached to Fluke 5111 instrument, range $-200^{\circ} \mathrm{C}-1000^{\circ} \mathrm{C}$, divisions $0.1^{\circ} \mathrm{C}$, Washington, US). This thermocouple had been calibrated in a certified laboratory in the last 6 months.

During exercise the criterion measure comprised of four hard-wired (HW) skin thermistors (Eltek U-Type EUS-U-VS5-0, Eltek Ltd, Cambridge, UK) connected to a datalogger (Grant Squirrel 1000 series, Grant Instruments, Cambridge, UK). The manufacturer stated accuracy 
was $\pm 0.2^{\circ} \mathrm{C}$. This type of device has been adopted as a criterion during similar validity comparisons (Kelechi et al. 2011; Buono et al. 2007, Burnham et al. 2006). The telemetry system (TT) comprised four skin thermistors (ELEU-U-VS-02-, Eltek U-Type, Eltek Ltd, Cambridge, UK) connected to a transmitter (Gen II GD38, Eltek, Cambridge, UK, dimensions $6 \times 8 \times 5 \mathrm{~cm}$ ). Data is transmitted wirelessly to a datalogger (Eltek RX250AL 1000 series Wireless Squirrel Logger, Eltek, Cambridge, UK), up to a distance of $2 \mathrm{~km}$. The datalogger was placed outside of the environment chamber approximately $3 \mathrm{~m}$ away. The manufacturer stated accuracy was $\pm 0.1^{\circ} \mathrm{C}$. Both dataloggers were synchronised and sampled every $30 \mathrm{~s}$ with minute average logged. Data was downloaded using Squirrelwire and Darca Plus for the HW and TT systems, respectively. The TC was a FLIR e40BX (Flir tools, Oregon, US) with 160x120 focal plane array, uncooled microbolometer with thermal sensitivity of $<0.045^{\circ} \mathrm{C}$ at $30^{\circ} \mathrm{C}, 7.5$ to $13 \mu \mathrm{m}$ spectral range, $60 \mathrm{~Hz}$ frame rate and a 'liveview' colour palette offering multiple spot analysis and area average functions. The manufacturer stated accuracy was $\pm 2{ }^{\circ} \mathrm{C}$ or $\pm 2 \%$. Emissivity was set at $e=0.98$ in accordance with the data of Steketee (1973).

\subsection{Procedures}

\subsubsection{Waterbath}

All thermistors and the criterion thermocouple (CT) were affixed within a $3 \mathrm{~cm}^{2}$ area, each was separated by $1 \mathrm{~cm}$, in the centre of the top surface of a cast iron block (dimensions: $15 \mathrm{x}$ $12 \times 12 \mathrm{~cm}$ ) placed in a waterbath (Fischer Scientific DMU19). Whilst a waterbath allows comparison of tools throughout a range of temperatures, water is not an appropriate body to measure using infrared thermometry. Thus, the waterbath provided controlled plateau temperatures, with the metal block providing the thermal surface for measurements. The thermal conductivity of iron results in a uniform temperature which helps avoid erroneous readings from convection currents within a large waterbath. The metal block was submerged to within $1 \mathrm{~mm}$ of the surface, which remained dry at all times. Breathable film patches (Tegaderm 1632W, 3M, UK) fastened all sensors and ensured thermistors remained in contact and perpendicular to the surface. The same patches were used during exercise trials to maintain consistency of any micro-climate effect. Black electrical tape with a known emissivity of 0.95 marked the TC measurement site. 
The camera was mounted one metre above the block, at an angle of $90^{\circ}$ to the plane of the block, with reflected environmental temperature and environmental conditions adjusted accordingly. The incorporated laser pointer ensured readings were consistently taken from the centre of the designated area. Both dataloggers were set to sample and log temperature values every minute, with TC and CT temperatures recorded each minute.

\subsubsection{Exercise test}

Upon arrival, participants self-inserted a single-use rectal probe (Henleys Medical, UK, Meter logger Model 401, Yellow Springs Instruments, Missouri, USA) $10 \mathrm{~cm}$ beyond the anal sphincter. Thermistors were then attached to the mid-belly of the pectoralis major, biceps brachii, rectus femoris and gastrocnemius on the right of the body. After shaving surface hair and cleaning with a sterilizing wipe, thermistors from both HW and TT were attached to each site using a film patch as in the waterbath procedures. Participants completed all trials in running trainers, sports shorts and without a t-shirt.

Participants then entered the environmental chamber (TISS, Hampshire, UK) with conditions (mean [sd]) $31.9(1)^{\circ} \mathrm{C}, 61(8.9) \%$ relative humidity. Such conditions provide a valid extreme environment within which to assess environmental physiology measurement tools as they represent the average conditions in Rio de Janeiro in the summer months when large sporting competitions are held. Environmental conditions were noted at the beginning, middle and end of the trial using a heat stress meter (HT30, Extech Instruments, USA). The trial began with participants sitting for 40 minutes with measurements taken every five minutes. All thermal camera measurements were taken handheld, at a distance of $1 \mathrm{~m}$, with the camera at $90^{\circ}$ to the relevant site as per the manufacturer's instructions. Temperatures were taken from the spot analysis function which displays the live temperature of an area within the viewfinder. The measurement site for the thermal camera was $1 \mathrm{~cm}$ adjacent to the edge of the film patch fixing the thermistors. This equated to a distance of $3 \mathrm{~cm}$ between the furthest thermistor and TC measurement site at each anatomical location. After 40 minutes a five minute warm-up at $8 \mathrm{~km} \cdot \mathrm{h}^{-1}$ was completed on a motorized treadmill (Woodway ELG2, Weil am Rhein, Germany) before participants began an incremental exercise test with starting speed between $8-10 \mathrm{~km} \cdot \mathrm{h}^{-1}$. Each participant completed five stages of three minutes, with speed increasing by $1 \mathrm{~km} \cdot \mathrm{h}^{-1}$. At the end of each stage the participant would straddle the treadmill belt and the thermal camera would be used to measure $\mathrm{T}_{\mathrm{SKIN}}$ at each site; the procedure took 
approximately $30 \mathrm{~s}$. At the end of the test nude body mass was recorded before participants were actively cooled using a large fan and cold drinks.

\subsection{Statistical Analysis}

\subsubsection{Waterbath}

Linear regression analysis was used to derive correction formulae for each measurement tool, relative to the criterion thermocouple. In order to develop robust formulae, all data from both day one and day two of the waterbath, was included, which equated to fourteen temperature measures (seven each day) within the range $25-40^{\circ} \mathrm{C}$ and two hundred and eighty data points for each equation. However, statistical analyses were conducted on the measures of temperatures taken over a typical range of values that would be expected during exercise. These temperatures were $33^{\circ} \mathrm{C}, 35^{\circ} \mathrm{C}$ and $38^{\circ} \mathrm{C}$. Validity and reliability comparisons were made on the grouped data for each tool, rather than at each temperature $\left(33,35,38^{\circ} \mathrm{C}\right)$. Data was corrected to one decimal place before analysis as CT and TC are precise to $0.1^{\circ} \mathrm{C}$ whereas HW and TT read to $0.01^{\circ} \mathrm{C}$. Mean values of the four thermistors in each system are reported, although data from individual thermistors was adjusted based on CT and the corrected values used in subsequent analysis. Differences between tools (validity) for raw and corrected data were investigated using a two way repeated measures ANOVA (correction*tool) with Bonferroni adjustments.

Additionally, the following battery of relative and absolute reliability statistics was calculated for each tool; mean bias, typical error of the measure (TEM), calculated from the standard deviation of the mean difference for each pair of trials using the formula $\mathrm{TE}=\mathrm{SD}_{(\mathrm{diff})} / \sqrt{2}$ and expressed as a mean coefficient of variation (CV), intra-class correlation (ICC) and limits of agreement (LOA). Reliability comparisons compared waterbath day 1 data against day 2 data. To eliminate variation from the waterbath itself, all of day 2 data was corrected based on a linear regression equation formed from the two criterion datasets. This prevented a systematic difference between trials, such as the failure to achieve precisely the same plateau temperature on day 2 which would invalidate reliability analyses of individual tools.

Validity comparisons were completed on waterbath day 1 data. Similar statistics were calculated for HW, TT and TC relative to the criterion to assess validity; mean bias, ICC, typical error of the estimate (TEE), providing standard or typical error of the predicted y- 
value for each x, and LOA. Differences between trials for each tool were investigated using two way repeated measures ANOVA (tool*trial) with Bonferroni post hoc adjustments. Statistical tests were completed using SPSS 20 (SPSS Inc, Chicago, USA) with significance set at $p<0.05$ throughout. Data are presented as mean \pm SD.

\subsubsection{Exercise test}

Analysis of $\mathrm{T}_{\mathrm{SKIN}}$ measurements was completed using the derivative calculation mean $\mathrm{T}_{\mathrm{SKIN}}$ using the formula of Ramanathan (1964):

Mean $\mathrm{T}_{\mathrm{SKIN}}=0.3\left(\mathrm{~T}_{\mathrm{CHEST}}+\mathrm{T}_{\mathrm{ARM}}\right)+0.2\left(\mathrm{~T}_{\mathrm{THIGH}}+\mathrm{T}_{\mathrm{CALF}}\right)$

Two way ANOVA (trial*time) with Bonferroni correction were used to identify differences between exercise trials for each tool (reliability). This included a comparison of the entire dataset from trial 1 against trial 2 data (main effect trial) to assess whether a systematic change had occurred between trials which may affect the interpretation of other statistics. A two way ANOVA (tool*time) was used to identify differences between tools (validity).

Sweat rate $\left(\mathrm{L} . \mathrm{hr}^{-1}\right)$ was calculated from the difference in pre and post nude body mass divided by the individual exercise duration.

\subsubsection{Analytical limits}

Analytical limits may assist in completing an objective and robust assessment of a measure (Atkinson \& Nevill 1998). Such limits can be predefined on what constitutes a meaningful physiological change, limits adopted by similar research and the precision of the criterion thermometer. The a priori analytical limits are shown in Table 1.

Table 1 here. 


\section{Results}

\subsubsection{Waterbath reliability comparison}

A difference was observed between all day 1 and all day 2 data $(p=0.01)$, however this did not remain after day 2 data were corrected based on the differences measured by the criterion thermocouple $(p=0.658)$ using the correction formula $\gamma=(1.009 x)+-0.365$. The raw data also displayed differences between days for every tool. After correction, this difference was eliminated for CT ( $p=0.124)$, but remained for all other tools (Table 2).

A summary of reliability comparisons are shown in Table 2, with uncorrected data plotted in Figure 1. Prior to correction, all tools displayed a mean bias below $0.2^{\circ} \mathrm{C}$. Correction reduced the mean bias for both HW and TT, but a small bias remained for TC. Absolute typical error (TEM), relative typical error (CV) and ICC calculated from the raw data (Table 2) were acceptable against the a priori analytical limits for all tools (Table 1). As a linear correction factor was applied to the data, the variation in differences between trials did not change, so TEM and the associated coefficients of variation remained the same after correction.

Acceptable LOA were observed for TT, with HW marginally exceeding the limits of $0.3^{\circ} \mathrm{C}$ and TC displaying the largest range.

\section{Figure 1 here}

\section{Table 2 here}

\subsubsection{Waterbath validity comparison}

Variation in block temperature was low throughout each temperature plateau period with mean standard deviation across all temperatures below $0.07^{\circ} \mathrm{C}$. Indicated water temperature was greater than displayed by $\mathrm{CT}$ for each temperature (block: water, $32.8: 34^{\circ} \mathrm{C}, 34.9: 37^{\circ} \mathrm{C}$, $38.1: 40^{\circ} \mathrm{C}$ ). Individual corrections were made to the data of each thermistor. Mean values from the four thermistors of both HW and TT systems produced the following equations; HW $=\gamma=(0.978 x)+0.484$ and TT $=\gamma=(1.019 x)+-0.518$. The formula used to correct all TC data was $\gamma=(1.146 x)+-3.121$. Formulae were derived from the fourteen plateau temperatures and provided TEE across this range of $0.13^{\circ} \mathrm{C}, 0.13^{\circ} \mathrm{C}$ and $0.1^{\circ} \mathrm{C}$ for $\mathrm{HW}, \mathrm{TT}$ 
and TC, respectively. The largest error for an individual thermistor was $0.18^{\circ} \mathrm{C}$, with mean TEE of $0.16^{\circ} \mathrm{C}$ for $\mathrm{HW}$ and $0.14^{\circ} \mathrm{C}$ for TT.

Prior to correction, the accuracy of each tool was very close to the manufacturer stated accuracy and all improved following correction (Table 2). Only TT displayed a mean bias below $0.2^{\circ} \mathrm{C}$, although $\mathrm{HW}$ nearly achieved this, only $0.02^{\circ} \mathrm{C}$ greater. The largest error was observed for TC, with raw mean bias ten times greater than the limit. Correction brought all tools within an acceptable level of bias. Significant differences from CT were observed for all tools in the raw data, but only for HW after correction $(p<0.001)$, with the corrected data significantly different to the raw data $(p<0.001)$. After correction, all devices displayed acceptable levels of absolute and relative TEE, whilst correlations were just below the a priori acceptable limit. Limits of agreement were acceptable for HW and TT pre and post correction, with a difference of just $0.01^{\circ} \mathrm{C}$ preventing TC meeting this limit.

\section{Table 3 here}

\subsubsection{Skin temperature reliability at rest and during exercise}

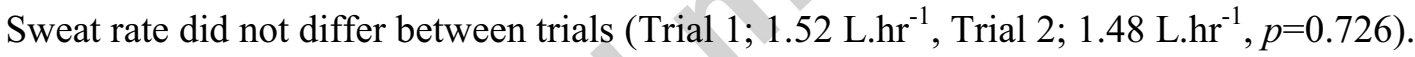
No differences in $\mathrm{T}_{\mathrm{SKIN}}$ were observed between trials $(p=0.137)$ for HW (Figure 2$)$. The HW system displayed a consistently small mean bias with a mean value of $0.01^{\circ} \mathrm{C}$ across rest and $0.18^{\circ} \mathrm{C}$ during exercise (Table 4). Across the statistics adopted, the largest differences occurred during the first 20 minutes of rest, with the greatest reliability after 30 minutes of rest. Initially TE was high $\left(0.53^{\circ} \mathrm{C}\right)$, but improved throughout the rest period $\left(\operatorname{mean}=0.34^{\circ} \mathrm{C}\right)$, reaching $0.2^{\circ} \mathrm{C}$ after 30 minutes and remaining just above the analytical limit throughout exercise (mean $\left.=0.31^{\circ} \mathrm{C}\right)$. Similarly, LOA was initially high $\left(1.47^{\circ} \mathrm{C}\right.$ after 10 minutes $)$, but acceptable at the end of rest $\left(35\right.$ minutes; $0.56^{\circ} \mathrm{C}$, mean $\left.=0.95^{\circ} \mathrm{C}\right)$. This further improved during exercise, with the mean value $0.86^{\circ} \mathrm{C}$. Correlation between the trials across rest $(r=0.67)$ and exercise $(r=0.62)$ was low, although after 30 minutes of the rest period the correlation increased $(r=0.84)$ to a level just below the predefined limit. 
No main effect between trials was observed $(p=0.343)$ for TT, however a time*trial interaction was present $(p=0.040)$ with differences during the final two exercise stages (Figure 2). A small mean bias was observed throughout the TT trial $2\left(-0.05^{\circ} \mathrm{C}\right)$ which was within acceptable limits, as was bias during rest $\left(-0.1^{\circ} \mathrm{C}\right)$ and exercise $\left(-0.19^{\circ} \mathrm{C}\right)$. Typical error within $\mathrm{TT}$ was greatest at the start of rest $\left(0.48^{\circ} \mathrm{C}\right)$, reducing to $0.29^{\circ} \mathrm{C}$ after 30 minutes, and remained low for the remainder of the trial (mean during exercise $0.24^{\circ} \mathrm{C}$, overall mean $0.31^{\circ} \mathrm{C}$ ), either below or very close to the acceptable limit. As with $\mathrm{HW}$, despite overall correlation for the entire protocol being below $0.9(r=0.74)$, points of strong agreement were observed for TT, in particular during exercise with correlation coefficients of $r=0.89,0.95$ and 0.96 for the final three stages.

A main effect was observed between trials $(p=0.023)$ for TC reflecting a systematic difference from trial 1 to trial 2 . Similarly a trial*time interaction was observed $(p=0.001)$ with differences in TC identified from the second exercise stage and continuing to the end of the trial (Figure 2). Agreement was poor for all statistics with none consistently meeting the acceptable limits (Table 4). A large negative bias was observed throughout trial $2\left(-0.65^{\circ} \mathrm{C}\right)$.

\section{Figure 2 here}

\subsubsection{Skin temperature validity comparison}

A main effect for tool $(p=0.002)$ was observed with differences between HW and TT $(p=0.03)$ and HW and TC $(p=0.007)$. A tool*time interaction $(p<0.001)$ was also observed with differences displayed in Table 5. A tabular report is shown in Table 5. The TT system showed good agreement with HW throughout the protocol. Mean bias was consistently low (mean: $-0.18^{\circ} \mathrm{C}$ ), achieving the predefined limit. This is supported by low mean typical error $\left(0.18^{\circ} \mathrm{C}\right)$ and strong correlation $(r=0.92)$. Similarly, mean LOA are narrow and within the acceptable limits $\left(0.39^{\circ} \mathrm{C}\right)$. Unlike TT, TC did not show good agreement with HW. A large bias was recorded throughout rest $\left(-0.87^{\circ} \mathrm{C}\right)$ and exercise $\left(-1.92^{\circ} \mathrm{C}\right)$ phases. Typical error consistently exceeded the limits and correlations were low throughout the trial (mean $r=0.45)$. These errors translated into large limits of agreement, consistently above the predefined limit $\left(1.30^{\circ} \mathrm{C}\right)$. 


\section{Discussion}

\subsection{Overview}

Assessing novel tools in a controlled, static environment as well as ecologically valid situations allows objective assessments of measurement accuracy and improved interpretation of data. A telemetry thermistor system (TT) offers a technologically similar, but more convenient option to traditional hard-wired systems. Thermal cameras (TC) measure the emitted infrared radiation from a body, permitting live non-contact infrared measurements, but have not previously been assessed across a range of running speeds in a hot, humid environment. The aim of this study was to compare the validity and reliability of these measurement tools when measuring $\mathrm{T}_{\text {SKIN }}$ whilst resting and running in a hot and humid environment. As expected, hard-wired thermistors (HW) demonstrated good agreement with the criterion thermocouple (CT) during the initial waterbath comparison and were reliable between trials. The TT system demonstrated the smallest error and greatest agreement with CT during static waterbath measurement. This system also performed well when measuring $\mathrm{T}_{\mathrm{SKIN}}$ at rest and during exercise, displaying the least error and largest correlations between trials, as well as the strongest agreement with the criterion suggesting it is appropriate for use within environmental physiology research. The thermal camera also demonstrated a small error during the waterbath measures, although a large systematic bias was detected. Using the current protocol, the camera did not perform as well as the other devices when providing live, handheld measurements of $\mathrm{T}_{\text {SKIN }}$ during exercise and we would not recommend it for use in this manner, as it has a tendency to under-read during exercise which presents safety implications.

\subsubsection{Waterbath validity comparison}

The correction of collected data based on a criterion measure has been advocated by previous research (Harper-Smith et al. 2010). This in-house calibration procedure is time consuming and requires specialist equipment, but is relatively inexpensive and the differences between raw and corrected data in this study suggest it is worthwhile when accurate results are required. Furthermore, completing this process prior to subsequent human testing will assist in partitioning error into biological, environmental and random error, incorporating the 
equipment error itself. Prior to correction, overall reliability from both HW and TT was acceptable based on the predefined analytical limits (Table 1). Such limits were adopted based on what constitutes a meaningful physiological change, the limits adopted by similar research and the precision of the criterion thermometer. Of particular note was the mean bias $\left(2^{\circ} \mathrm{C}\right)$ and $\operatorname{LOA}\left(0.74^{\circ} \mathrm{C}\right)$ observed in $\mathrm{TC}$, which despite meeting the manufacturer stated accuracy, far exceeds the acceptable error $\left(0.2^{\circ} \mathrm{C}\right)$ for safe and meaningful measurements of $\mathrm{T}_{\text {SKIN. }}$. Although TC over-estimated across all waterbath temperatures, a heteroscedastic trend is observed with the greatest errors occurring at the highest temperatures (Figure 1). Within the range assessed, the indicated water temperature was above that measured by CT. Despite being setup in accordance with manufacturer's guidelines, it is possible TC partially detected water temperature rather than solely the metal block. Thermal cameras are usually calibrated by taking readings on an electronically heated black body and corrected as necessary. The purpose of the waterbath was not to calibrate the tools, but to allow a simultaneous comparison of all tools to facilitate a communal correction to help detect differences. This method was adopted given the traditional method for thermistor comparison was inappropriate for including TC and following correspondence with the TC manufacturer. These results may indicate a flaw for TC when measuring against a background which is hotter than the object in question. These errors were minimised after correction, such that TC accuracy was acceptable in terms of mean bias, no significant difference and low CV. Other statistics were extremely close to acceptable limits.

\subsubsection{Waterbath reliability comparison}

Data collected during trial 2 of the waterbath analysis were corrected based on the differences observed by the criterion between trials. This was necessary due to a difference between plateau temperatures $\left(0.1^{\circ} \mathrm{C}, p<0.001\right)$ on day two. Correction allowed the remaining differences to be attributed to the tools themselves rather than the waterbath conditions. The correction reduced the mean bias for all tools and eliminated the significant difference between trials for HW, but not for TT and TC. However, significance testing alone does not preclude a device from being considered reliable or valid, which is why a battery of statistics was completed. When a significant difference is identified, it is typically the magnitude of this difference that is relevant to the end user (Hopkins et al. 2009). Cohen's d effect sizes 
state these differences to be trivial. Therefore, where a significant difference was observed, in the context of the accepted limits the difference was not critical. TT was the most reliable tool, achieving all other a priori limits, both with the raw and corrected data. Wired thermistors and TC failed to meet the acceptance levels for TE and LOA, however both displayed low mean bias, strong correlations and low $\mathrm{CV}$, so were deemed to have performed reliably.

\subsection{Skin temperature validity comparison}

During rest and exercise HW recorded a consistently higher temperature than TT and TC. However, there was strong agreement between HW and TT, with all a priori limits achieved, meaning TT can be considered a valid measurement tool. Conversely, TC showed poor agreement and could not be considered valid for measurement of $\mathrm{T}_{\text {SKIN }}$ using this method or similar conditions with an error of $2^{\circ} \mathrm{C}$ potentially affecting mean body temperature by $0.4^{\circ} \mathrm{C}$.

During exercise, both TT and TC recorded lower temperatures than HW, despite reading higher during the waterbath. The mean difference from HW for TT was small $\left(-0.18^{\circ} \mathrm{C}\right)$ with the largest difference during exercise $\left(-0.25^{\circ} \mathrm{C}\right)$ still within predefined acceptable limits $\left(<0.3^{\circ} \mathrm{C}\right)$. In the context of previous research on $\mathrm{T}_{\text {SKIN }}$ measurements, such differences appear very small, with Harper-Smith et al. (2010) reporting differences of $0.26-1.36^{\circ} \mathrm{C}$ between thermistors and iButtons. Furthermore, when retest variation of both HW and TT are considered, this difference becomes negligible and may not even exist. Such results may afford opportunities to measure $\mathrm{T}_{\text {SKIN }}$ in extreme environments using $\mathrm{TT}$ with the receiver unit needing only to be within $2 \mathrm{~km}$ of the exercising individual. Until now, the potential for this type of research has been limited by the need for trailing wires when using HW systems.

However, the differences observed in $\mathrm{T}_{\mathrm{SKIN}}$ from TC were sizeable. Utilising $\mathrm{TC}$ in a dynamic, ecologically valid situation is in contrast to the techniques adopted in the majority of previous research with thermal cameras that has shown broadly encouraging results (Merla et al. 2010; Ferreira et al. 2008; Chudecka \& Lubkowska 2012), albeit not unanimously (Fernandes et al. 2014). Specifically, tripod mounted cameras have been used to generate thermograms of participants who have spent up to 40 minutes in thermo-neutral conditions. Thermograms are then analysed post hoc using area averages to identify temperatures within 
specific anatomical regions. For an exercise physiologist, the problem with such an approach is the lack of real-time data upon which decisions can be made. Consequently, the rationale for including TC in this study was to examine whether TC could provide accurate and reliable data through the live-view function during an exercise test. Johnstone et al. (2012) also reported poor validity of an IR sensor within a physiological monitoring system that provided live data during exercise in the heat. Despite an acceptable mean bias $\left(0.49^{\circ} \mathrm{C}\right)$, they reported a large random error with the LOA range $-1.36-4.14^{\circ} \mathrm{C}$. There are a range of difficulties associated with exercise that may explain the erroneous readings in both studies and why these findings differ from previous research that has successfully used this technology. A fundamental difference between thermistor and IR measurement techniques is covering of the measurement site. Thermistors were attached using breathable film patches, which may lessen a micro-climate effect relative to other fixation methods, but may still over-estimate relative to uncovered skin (Tyler 2011). Whilst secure fixation for thermistors is necessary to minimise small angular changes during exercise, the precise angle and distance of IR measurements in both studies was not fixed, which could lead to increased measurement error (Hershler et al. 1992). An aim of this study was to assess tools taking live measurements in an ecologically valid setting. As such, a widely used incremental, discontinuous protocol was completed which permitted short, but regular measurement opportunities at the end of each stage. Temperatures at four body sites were required in approximately $30 \mathrm{~s}$ and although precautions were taken, some variation in angle between measurements is to be expected. The short measurement period prevented ensuring that the skin was completely dry for measurements. Protocol sweat rates were approaching $2 \mathrm{~L} . \mathrm{h}^{-1}$, which compromised drying the skin and completing measurements within the permitted time. Water may alter the emissivity of the skin, so causing the camera to under-read; a trend observed by Johnstone et al. (2012). Further, the effect of the waterbath correction procedure on subsequent exercising values should be considered. As previously mentioned TC may have partially detected the surrounding water temperature, rather than simply the metal block, resulting in over-estimation of values. In this instance the correction formula may be inaccurate, falsely suggesting TC under-estimated during exercise. However, as a linear correction was applied to the data, the high levels of random error TC displayed throughout $\mathrm{T}_{\text {SKIN }}$ measurements remain an obstacle for dynamic use. 
Modifications to the TC protocol are required if accurate results are going to be yielded from such a test. Subsequent pilot testing in our laboratory (unpublished data) suggests that improved accuracy is possible with this model of camera when camera positions are fixed and longer periods of time are available for measurements to be taken. When transferring tools to applied situations, a compromise must be made between maximising measurement accuracy and maintaining ecological validity of the protocol. Consequently, whilst TC may still have a role to play in static, controlled situations within environmental physiology, using the current protocol it cannot be considered a valid alternative to either of the thermistor systems for live monitoring of $\mathrm{T}_{\mathrm{SKIN}}$ during exercise.

\subsubsection{Skin temperature reliability comparison}

The reliability of both thermistor systems was acceptable throughout the exercise tests, whilst TC again displayed large errors. The lack of difference in sweat rate between trials would indicate that TC did not under-read as a consequence of an adaptation eliciting a greater sweat response from the heat exposure during trial 1. Moreover, allowing 7 days between trials is likely to have prevented this effect (Barnett \& Maughan 1993). The graphs for both HW and TT (Figure 2) display converging means throughout the rest period, with dissociation during the latter part of exercise. This supports the need for a long stabilisation period and suggests that temperature differences occurred as exercise intensity rises. Reduced reliability is associated with challenges to homeostasis and this occurs throughout incremental tests where thermal equilibrium is never achieved. Other literature has made comparisons during steady-state exercise (Buono et al. 2007; Smith et al. 2010), so the small differences observed may be a characteristic of this test and the reliability of all tools may improve when examined under similar circumstances. 
18

\section{Conclusion}

A telemetry thermistor system offers a valid and reliable alternative measure of skin temperature to traditional hard-wired thermistors. Such a system may provide for data collection up to a range of $2 \mathrm{~km}$ from the datalogger allowing ecologically valid measurements to be taken in the field. Thermal cameras may still be useful tools for measuring skin temperature in static and controlled environments, however their use is not recommended for live monitoring during exercise. 


\section{References}

Atkinson, G. \& Nevill, A., 1998. Statistical methods for assessing measurement error (reliability) in variables relevant to sports medicine. Sports Medicine, 26(4), pp.217-238.

Barnett, a \& Maughan, R.J., 1993. Response of unacclimatized males to repeated weekly bouts of exercise in the heat. British journal of sports medicine, 27(1), pp.39-44.

Buono, M.J. et al., 2007. Comparison of infrared versus contact thermometry for measuring skin temperature during exercise in the heat. Physiological measurement, 28(8), pp.855-9.

Burnham, R.S., McKinley, R.S. \& Vincent, D.D., 2006. Three types of skin-surface thermometers: a comparison of reliability, validity, and responsiveness. American journal of physical medicine \& rehabilitation / Association of Academic Physiatrists, 85(7), pp.553-8.

Chudecka, M. \& Lubkowska, A., 2012. The Use of Thermal Imaging to Evaluate Body Temperature Changes of Athletes During Training and a Study on the Impact of Physiological and Morphological Factors on Skin Temperature. Human Movement, 13(1), pp.33-39.

Costello, J.T. et al., 2012. The use of thermal imaging in assessing skin temperature following cryotherapy: a review. Journal of Thermal Biology, 37(2), pp.103-110.

Fernandes, A.D.A. et al., 2014. Measuring skin temperature before, during and after exercise: a comparison of thermocouples and infrared thermography. Physiological measurement, 35(2), pp.189-203.

Ferreira, J.J. a et al., 2008. Exercise-associated thermographic changes in young and elderly subjects. Annals of biomedical engineering, 36(8), pp.1420-7.

Hershler, C. et al., 1992. Assessment of an infra-red non-contact sensor for routine skin temperature monitoring: a preliminary study. J. Med Eng. Technol, 16(3), pp.117-122.

Hopkins, W.G. et al., 2009. Progressive statistics for studies in sports medicine and exercise science. Medicine and science in sports and exercise, 41(1), pp.3-13.

Jay, O. et al., 2007. Estimating changes in mean body temperature for humans during exercise using core and skin temperatures is inaccurate even with a correction factor. Journal of applied physiology (Bethesda, Md. : 1985), 103(2), pp.443-51.

Jay, O. \& Kenny, G., 2007. The determination of changes in body heat content during exercise using calorimetry and thermometry. Journal of the human-environmental system, 10(1), pp.19-29.

Johnstone, J. a et al., 2012. Bioharness $\left({ }^{\mathrm{TM}}\right)$ multivariable monitoring device: part. I: validity. Journal of sports science \& medicine, 11(3), pp.400-8.

Kelechi, T.J., Good, A. \& Mueller, M., 2011. Agreement and Repeatability of an Infrared Thermometer. Journal of Nursing Measurement, 19(1), pp.55-64.

Kim, J.-H. et al., 2013. Application of thermoregulatory modeling to predict core and skin temperatures in firefighters. International Journal of Industrial Ergonomics, 43(1), pp.115-120. 
Merla, A. et al., 2010. Thermal imaging of cutaneous temperature modifications in runners during graded exercise. Annals of biomedical engineering, 38(1), pp.158-63.

Ng, E.Y.K., Kaw, G.J.L. \& Chang, W.M., 2004. Analysis of IR thermal imager for mass blind fever screening. Microvascular research, 68(2), pp.104-9.

Ramanathan, N.L., 1964. a New Weighting System for Mean Surface Temperature of the Human Body. Journal of applied physiology, 19, pp.531-3.

Ring, E.F.J. \& Ammer, K., 2012. Infrared thermal imaging in medicine. Physiological measurement, 33(3), pp.R33-46.

Roberts, M. \& Wenger, C., 1979. Control of skin circulation during exercise and heat stress. Medicine and science in sports, 11(1), pp.36-41.

Roy, R., Boucher, J.P. \& Comtois, A.S., 2006. Validity of infrared thermal measurements of segmental paraspinal skin surface temperature. Journal of manipulative and physiological therapeutics, 29(2), pp.150-5.

Selfe, J. et al., 2006. An accurate and reliable method of thermal data analysis in thermal imaging of the anterior knee for use in cryotherapy research. Archives of physical medicine and rehabilitation, 87(12), pp.1630-5.

Sherman, R.A., Wideman, A.L. \& Karstetter, K.W., 1996. relative skin temperature. Journal of Rehabilitation Research and Development, 33(4), pp.377-386.

Smith, a D.H. et al., 2010. The validity of wireless iButtons and thermistors for human skin temperature measurement. Physiological measurement, 31(1), pp.95-114.

Steketee, J., 1973. Spectral emissivity of skin and pericardium. Physics in medicine and biology, 18(5), pp.686-94.

Torii, M. et al., 1992. Fall in skin temperature of exercising man. British journal of sports medicine, 26(1), pp.29-32.

Tyler, C.J., 2011. The effect of skin thermistor fixation method on weighted mean skin temperature. Physiological measurement, 32(10), pp.1541-7.

Winget, C., 1985. Circadian rhythms and athletic performance. Medicine \& Science in Sports \& Exercise in Sports \& Exercise, 17(5), pp.498-516.

Zaproudina, N. et al., 2008. Reproducibility of infrared thermography measurements in healthy individuals. Physiological measurement, 29(4), pp.515-24. 


\section{Figure Captions:}

Figure 1 Mean uncorrected data from hard-wired, telemetry system and thermal camera during each waterbath plateau temperature across the range $25-40^{\circ} \mathrm{C}$. The dark line represents the criterion thermocouple (CT) against which thermistors and camera data was corrected.

Figure 2: Mean (SD) reliability of wired thermistors, telemetry thermistors and thermal camera measuring skin temperature. ' $\mathrm{R}$ ' = rest, 'Ex' = exercise. ' $*$ ' denotes a difference between trials $(p<0.05)$.

\section{Highlights}

- The purpose of this study was to investigate the validity and reliability of skin temperature measurements using a telemetry thermistor system and a thermal camera.

- Assessments were completed on a solid body in a thermostatically controlled waterbath and on participants at rest and during exercise in a hot environment.

- Post hoc calibration based on waterbath results displayed good validity and reliability for the thermistor system but not the thermal camera.

- The use of telemetry thermistors are recommended for measurements in the field where traditional methods may be impractical.

- Thermal cameras may be better suited to controlled, static situations.

\section{Tables:}

Table 1. Analytical limits adopted for both part 1 (waterbath) and part 2 ( $\mathrm{T}_{\text {SKIN }}$ measurement) of this study. Sig = relative to criterion, with thermocouple the criterion during the waterbath and hard wired thermistors criterion during exercise.

\begin{tabular}{ccccccc}
\hline & $\begin{array}{c}\Delta \text { mean } \\
\left({ }^{\circ} \mathbf{C}\right)\end{array}$ & Sig. & $\begin{array}{c}\text { TEE/TE } \\
\text { M }\left({ }^{\circ} \mathbf{C}\right)\end{array}$ & TE & ICC & $\begin{array}{c}\text { LOA } \\
(\mathbf{C V} \%)\end{array}$ \\
& & & & & \\
& & & & & \\
\hline \multirow{2}{*}{ Waterbath } & $<0.2$ & $p>0.05$ & $<0.1$ & $<1 \%$ & $>0.9$ & $<0.3$ \\
& & & & & & \\
Exercise & $<0.5$ & $p>0.05$ & $<0.3$ & $<1 \%$ & $>0.9$ & $<0.9$ \\
& & & & & & \\
\hline
\end{tabular}


Columns left to right; change in mean ( $\Delta$ mean), statistical difference (Sig), typical error of the estimate (TEE)/measure (TEM), typical error as a coefficient of variation (TE[CV\%]), intraclass correlation coefficient (ICC) and limits of agreement (LOA).

Table 2: Reliability of wired thermistors, telemetry thermistors and thermal camera after correction to account for difference in bath temperature between trials 1 and 2 .

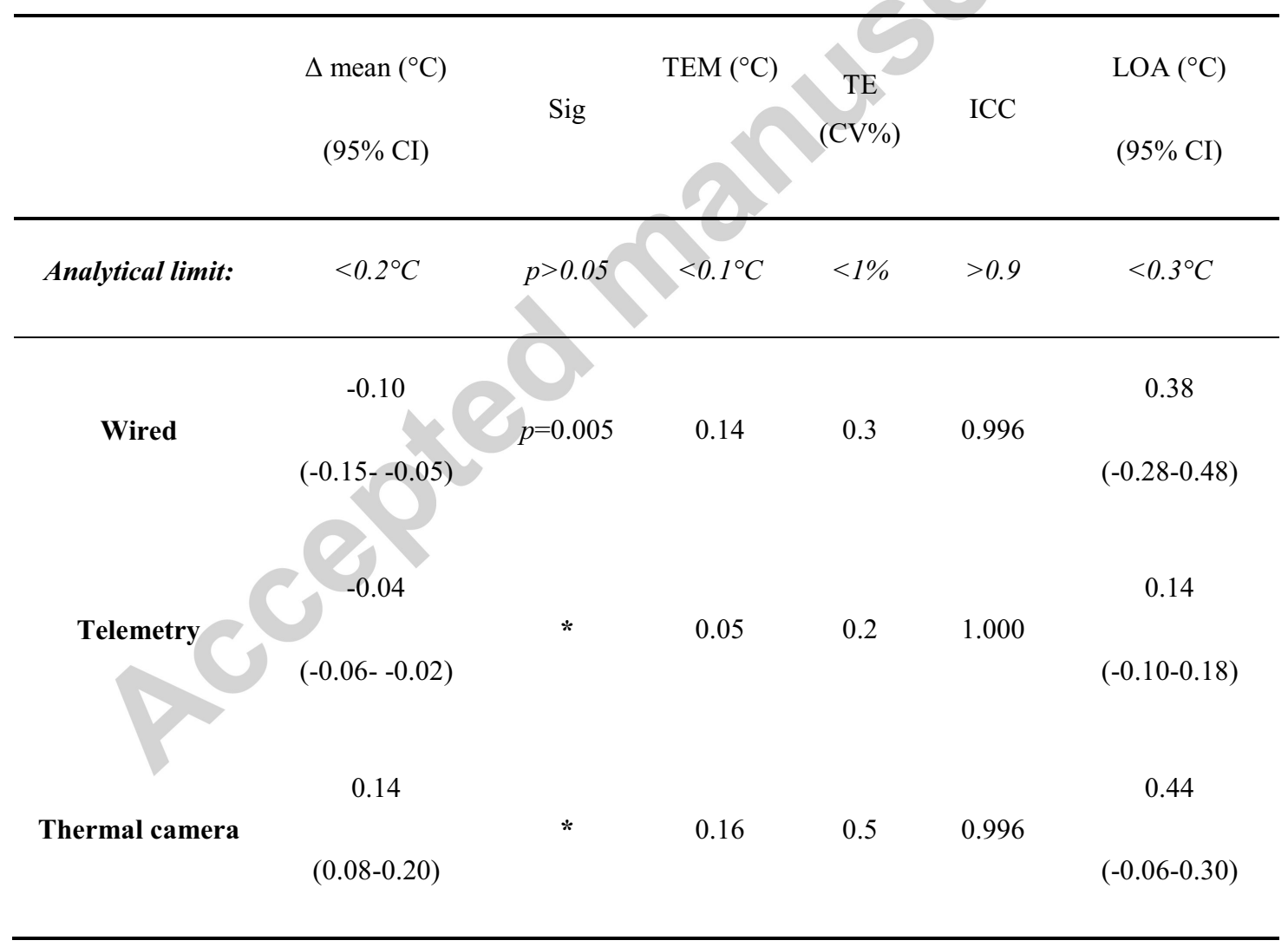

Columns left to right; change in mean between trials ( $\Delta$ mean), statistical difference (Sig), typical error of the measure (TEM), typical error as a coefficient of variation (TE[CV\%]), intraclass correlation coefficient (ICC) and limits of agreement (LOA). '*' denotes $p<0.001$, ' $95 \% \mathrm{CI}$ ' $=95 \%$ confidence interval. 
Table 3: Validity of wired thermistors, telemetry thermistors and thermal camera relative to the criterion thermocouple. Mean values from 33,35 and $38^{\circ} \mathrm{C}$ are presented.

\section{Raw data}

\begin{tabular}{|c|c|c|c|c|c|c|c|}
\hline & $\begin{array}{c}\text { Manufacturer } \\
\text { accuracy } \\
\left( \pm^{\circ} \mathbf{C}\right)\end{array}$ & $\begin{array}{c}\Delta \text { mean }\left({ }^{\circ} \mathrm{C}\right) \\
(95 \% \mathrm{CI})\end{array}$ & Sig & $\begin{array}{l}\text { TEE } \\
\left({ }^{\circ} \mathrm{C}\right)\end{array}$ & $\begin{array}{c}\text { TE } \\
(\mathrm{CV} \%)\end{array}$ & ICC & $\begin{array}{l}\text { LOA }\left({ }^{\circ} \mathrm{C}\right) \\
(95 \% \mathrm{CI})\end{array}$ \\
\hline $\begin{array}{c}\text { Analytical } \\
\text { limit: }\end{array}$ & & $<0.2^{\circ} \mathrm{C}$ & $p>0.05$ & $<0.1^{\circ} \mathrm{C}$ & $<1 \%$ & & $<0.3^{\circ} \mathrm{C}$ \\
\hline Wired & 0.2 & $\begin{array}{c}-0.22 \\
(-0.24--0.20)\end{array}$ & $*$ & 0.07 & 0.2 & 0.85 & $\begin{array}{c}0.13 \\
(-0.35--0.09)\end{array}$ \\
\hline Telemetry & 0.1 & $\begin{array}{c}0.15 \\
(0.13-0.17)\end{array}$ & & 0.07 & 0.2 & 0.86 & $\begin{array}{c}0.16 \\
(0.00-0.31)\end{array}$ \\
\hline $\begin{array}{l}\text { Thermal } \\
\text { camera }\end{array}$ & 2 & $\begin{array}{c}2.01 \\
(1.91-2.10)\end{array}$ & $*$ & 0.17 & 0.5 & 0.99 & $\begin{array}{c}0.74 \\
(1.26-2.75)\end{array}$ \\
\hline & & & orrected & & & & \\
\hline Wired & 0.2 & $\begin{array}{c}0.08 \\
(0.05-0.11)\end{array}$ & $*$ & 0.07 & 0.2 & 0.85 & $\begin{array}{c}0.21 \\
(-0.13-0.29)\end{array}$ \\
\hline Telemetry & 0.1 & $\begin{array}{c}0.02 \\
(0.00-0.04)\end{array}$ & $p=0.267$ & 0.08 & 0.2 & 0.86 & $\begin{array}{c}0.15 \\
(-0.13-0.17)\end{array}$ \\
\hline Thermal & 2 & -0.02 & $p=1.000$ & 0.16 & 0.5 & 0.86 & 0.31 \\
\hline
\end{tabular}


25

camera

$(-0.07-0.02)$

$(-0.34-0.29)$

Columns left to right; manufacturer stated accuracy, change in mean ( $\Delta$ mean), statistical difference (Sig), typical error of the estimate (TEE), typical error as a coefficient of variation (TE[CV\%]), intraclass correlation coefficient (ICC) and limits of agreement (LOA). '*' denotes $p<0.001$, ' $95 \% \mathrm{CI}$ ' $=95 \%$ confidence interval. 
Table 4: Reliability of wired thermistors, telemetry thermistors and thermal camera measuring skin temperature at rest and during exercise.

\begin{tabular}{|c|c|c|c|c|c|c|}
\hline & & $\begin{array}{c}\Delta \text { mean }\left({ }^{\circ} \mathrm{C}\right) \\
(95 \% \mathrm{CI})\end{array}$ & $\begin{array}{l}\text { TEM } \\
\left({ }^{\circ} \mathbf{C}\right)\end{array}$ & $\begin{array}{c}\text { TE } \\
(\mathrm{CV} \%)\end{array}$ & ICC & $\begin{array}{l}\operatorname{LOA}\left({ }^{\circ} \mathrm{C}\right) \\
(95 \% \mathrm{CI})\end{array}$ \\
\hline & $\begin{array}{l}\text { Analytical } \\
\text { limit: }\end{array}$ & $<0.5^{\circ} \mathrm{C}$ & $<0.3^{\circ} \mathrm{C}$ & $<1 \%$ & $>0.9$ & $<0.9^{\circ} \mathrm{C}$ \\
\hline & Rest & $0.01(-0.27-0.29)$ & 0.34 & 1 & 0.67 & $0.95(-0.95-0.94)$ \\
\hline \multicolumn{7}{|c|}{ HW } \\
\hline & Exercise & $0.18(-0.46-0.09)$ & 0.31 & 0.88 & 0.62 & $0.86(-0.62-1.09)$ \\
\hline & Rest & $0.10(-0.22-0.42)$ & 0.38 & 1.11 & 0.64 & $1.04(-1.14-0.94)$ \\
\hline & Exercise & $-0.19(-0.42-0.04)$ & 0.24 & 0.7 & 0.84 & $0.67(-0.48-0.87)$ \\
\hline & Rest & $-0.38(-0.83-0.07)$ & 0.53 & 1.58 & 0.52 & $1.46(-1.08-1.85)$ \\
\hline & Exercise & $-0.92(-1.35-0.49)$ & 0.5 & 1.5 & 0.56 & $1.40(-0.60-2.20)$ \\
\hline
\end{tabular}

Columns left to right; change in mean ( $\Delta$ mean), typical error of the measure (TEM), typical error as a coefficient of variation (TE[CV\%]), intraclass correlation coefficient (ICC) and limits of agreement (LOA). 'CI' $=95 \%$ confidence interval. 
Table 5: Tabular report of validity comparisons between hard wired thermistors, telemetry thermistors and thermal camera at rest and during exercise.

\begin{tabular}{|c|c|c|c|c|c|c|c|c|c|c|}
\hline & Rest 1 & Rest 2 & Rest 3 & Rest 4 & Rest 5 & $\begin{array}{l}\text { Exerci } \\
\text { se } 1\end{array}$ & $\begin{array}{l}\text { Exerci } \\
\text { se } 2\end{array}$ & $\begin{array}{l}\text { Exerci } \\
\text { se } 3\end{array}$ & $\begin{array}{l}\text { Exerci } \\
\text { se } 4\end{array}$ & $\begin{array}{l}\text { Exerci } \\
\text { se } 5\end{array}$ \\
\hline & $\begin{array}{l}10 \min \\
s\end{array}$ & $20 m i n s$ & 25 mins & 30mins & 35 mins & $4 m i n s$ & 8mins & $12 \operatorname{mins}$ & 16 mins & 20 mins \\
\hline $\begin{array}{l}\mathrm{HW}- \\
\text { mean } \\
(s d)\end{array}$ & $\begin{array}{l}33.81 \\
(0.44)\end{array}$ & $\begin{array}{l}33.93 \\
(0.52)\end{array}$ & $\begin{array}{l}34.10 \\
(0.43)\end{array}$ & $\begin{array}{l}34.10 \\
(0.39)\end{array}$ & $\begin{array}{l}34.16 \\
(0.41)\end{array}$ & $\begin{array}{l}34.75 \\
(0.50)\end{array}$ & $\begin{array}{l}35.26 \\
(0.31)\end{array}$ & $\begin{array}{l}35.19 \\
(0.31)\end{array}$ & $\begin{array}{l}35.19 \\
(0.40)\end{array}$ & $\begin{array}{l}35.25 \\
(0.56)\end{array}$ \\
\hline $\begin{array}{l}\text { TT - } \\
\text { mean } \\
(s d)\end{array}$ & $\begin{array}{l}33.72 \\
(0.47)\end{array}$ & $\begin{array}{l}33.77 \\
(0.46)\end{array}$ & $\begin{array}{l}33.96 \\
(0.38)\end{array}$ & $\begin{array}{l}33.94 \\
(0.39)\end{array}$ & $\begin{array}{l}34.05 \\
(0.40)\end{array}$ & $\begin{array}{l}34.51 \\
(0.54)\end{array}$ & $\begin{array}{l}35.02 \\
(0.32)\end{array}$ & $\begin{array}{l}34.96 \\
(0.45)\end{array}$ & $\begin{array}{l}34.95 \\
(0.56)\end{array}$ & $\begin{array}{l}35.02 \\
(0.69)\end{array}$ \\
\hline $\begin{array}{l}\Delta \text { mean } \\
\left({ }^{\circ} \mathrm{C}\right) \\
(95 \% \\
\mathrm{CI})\end{array}$ & $\begin{array}{l}-0.09 \\
(-0.23 \\
-0.05)\end{array}$ & $\begin{array}{l}-0.16 \\
(-0.34 \\
-0.02)\end{array}$ & $\begin{array}{l}-0.13 \\
(-0.27 \\
-0.00)\end{array}$ & $\begin{array}{l}-0.15 \\
(-0.29 \\
-0.02)\end{array}$ & $\begin{array}{l}-0.12 \\
(-0.26- \\
0.03)\end{array}$ & $\begin{array}{c}-0.23 * \\
(-0.34 \\
-0.12)\end{array}$ & $\begin{array}{c}-0.25 * \\
(-0.34 \\
-0.16)\end{array}$ & $\begin{array}{l}-0.22 \\
(-0.35 \\
-0.10)\end{array}$ & $\begin{array}{l}-0.24 \\
(-0.42 \\
-0.06)\end{array}$ & $\begin{array}{l}-0.24 \\
(-0.47 \\
-0.00)\end{array}$ \\
\hline $\begin{array}{l}\text { TEE } \\
(C V \%)\end{array}$ & $\begin{array}{l}0.21 \\
(0.6)\end{array}$ & $\begin{array}{l}0.25 \\
(0.7)\end{array}$ & $\begin{array}{l}0.20 \\
(0.6)\end{array}$ & $\begin{array}{l}0.20 \\
(0.6)\end{array}$ & $\begin{array}{l}0.20 \\
(0.6)\end{array}$ & $\begin{array}{l}0.15 \\
(0.4)\end{array}$ & $\begin{array}{l}0.11 \\
(0.3)\end{array}$ & $\begin{array}{l}0.10 \\
(0.3)\end{array}$ & $\begin{array}{l}0.15 \\
(0.4)\end{array}$ & $\begin{array}{l}0.26 \\
(0.7)\end{array}$ \\
\hline ICC & 0.91 & 0.92 & 0.91 & 0.90 & 0.91 & 0.97 & 0.96 & 0.92 & 0.92 & 0.92 \\
\hline $\begin{array}{l}\text { LOA } \\
\left({ }^{\circ} \mathrm{C}\right) \\
(95 \% \\
\text { CI })\end{array}$ & $\begin{array}{l}0.41 \\
(-0.32 \\
-0.50)\end{array}$ & $\begin{array}{l}0.45 \\
(-0.29 \\
-0.61)\end{array}$ & $\begin{array}{l}0.38 \\
(-0.24 \\
-0.51)\end{array}$ & $\begin{array}{l}0.38 \\
(-0.23 \\
-0.54)\end{array}$ & $\begin{array}{l}0.39 \\
(-0.27- \\
0.50)\end{array}$ & $\begin{array}{l}0.30 \\
(-0.07 \\
-0.53)\end{array}$ & $\begin{array}{l}0.21 \\
(0.04- \\
0.46)\end{array}$ & $\begin{array}{l}0.35 \\
(-0.13 \\
-0.57)\end{array}$ & $\begin{array}{l}0.46 \\
(-0.22 \\
-0.70)\end{array}$ & $\begin{array}{l}0.59 \\
(-0.36 \\
-0.83)\end{array}$ \\
\hline $\begin{array}{l}\text { HW - } \\
\text { mean } \\
(s d)\end{array}$ & $\begin{array}{l}33.81 \\
(0.44)\end{array}$ & $\begin{array}{l}33.93 \\
(0.52)\end{array}$ & $\begin{array}{l}34.10 \\
(0.43)\end{array}$ & $\begin{array}{l}34.10 \\
(0.39)\end{array}$ & $\begin{array}{l}34.16 \\
(0.41)\end{array}$ & $\begin{array}{l}34.75 \\
(0.50)\end{array}$ & $\begin{array}{l}35.26 \\
(0.31)\end{array}$ & $\begin{array}{l}35.19 \\
(0.31)\end{array}$ & $\begin{array}{l}35.19 \\
(0.40)\end{array}$ & $\begin{array}{l}35.25 \\
(0.56)\end{array}$ \\
\hline $\begin{array}{l}\mathrm{TC}- \\
\text { mean } \\
(s d)\end{array}$ & $\begin{array}{l}33.06 \\
(0.65)\end{array}$ & $\begin{array}{l}33.04 \\
(0.81)\end{array}$ & $\begin{array}{l}33.06 \\
(0.83)\end{array}$ & $\begin{array}{l}33.27 \\
(0.67)\end{array}$ & $\begin{array}{l}33.31 \\
(0.80)\end{array}$ & $\begin{array}{l}32.63 \\
(1.13)\end{array}$ & $\begin{array}{l}33.45 \\
(0.54)\end{array}$ & $\begin{array}{l}33.26 \\
(0.85)\end{array}$ & $\begin{array}{l}33.33 \\
(0.94)\end{array}$ & $\begin{array}{l}33.32 \\
(0.99)\end{array}$ \\
\hline $\begin{array}{l}\text { Change } \\
\text { in } \\
\text { mean } \\
\left({ }^{\circ} \mathrm{C}\right)\end{array}$ & $\begin{array}{l}-0.75 \\
(-1.19 \\
-0.31)\end{array}$ & $\begin{array}{l}-0.89 * \\
(-1.30 \\
-0.48)\end{array}$ & $\begin{array}{l}-1.04 * \\
(-1.46 \\
-0.61)\end{array}$ & $\begin{array}{l}-0.83 * \\
(-1.18 \\
-0.48)\end{array}$ & $\begin{array}{l}-0.85 \\
* * \\
(-1.29- \\
0.41)\end{array}$ & $\begin{array}{l}-2.12 * \\
(-2.93 \\
-1.31)\end{array}$ & $\begin{array}{l}-1.82 * \\
(-2.29 \\
-1.35)\end{array}$ & $\begin{array}{l}-1.93 * \\
(-2.39 \\
-1.46)\end{array}$ & $\begin{array}{l}-1.86 * \\
(-2.37 \\
-1.36)\end{array}$ & $\begin{array}{l}-1.94 * \\
(-2.50 \\
-1.37)\end{array}$ \\
\hline
\end{tabular}




\begin{tabular}{|c|c|c|c|c|c|c|c|c|c|c|}
\hline & Rest 1 & Rest 2 & Rest 3 & Rest 4 & Rest 5 & $\begin{array}{l}\text { Exerci } \\
\text { se } 1\end{array}$ & $\begin{array}{l}\text { Exerci } \\
\text { se } 2\end{array}$ & $\begin{array}{l}\text { Exerci } \\
\text { se } 3\end{array}$ & $\begin{array}{l}\text { Exerci } \\
\text { se } 4\end{array}$ & $\begin{array}{l}\text { Exerci } \\
\text { se } 5\end{array}$ \\
\hline & $\begin{array}{l}10 \min \\
s\end{array}$ & $20 \mathrm{mins}$ & 25 mins & 30 mins & 35 mins & 4 mins & 8mins & 12 mins & 16 mins & 20 mins \\
\hline $\begin{array}{l}\text { TEE } \\
(\mathrm{CV} \%)\end{array}$ & $\begin{array}{l}0.43 \\
(1.3)\end{array}$ & $\begin{array}{l}0.37 \\
(1.1)\end{array}$ & $\begin{array}{l}0.31 \\
(0.9)\end{array}$ & $\begin{array}{l}0.32 \\
(0.9)\end{array}$ & $\begin{array}{l}0.33 \\
(1.0)\end{array}$ & $\begin{array}{l}0.51 \\
(1.5)\end{array}$ & $\begin{array}{l}0.33 \\
(1.0)\end{array}$ & $\begin{array}{l}0.22 \\
(0.6)\end{array}$ & $\begin{array}{l}0.24 \\
(0.7)\end{array}$ & $\begin{array}{l}0.45 \\
(1.3)\end{array}$ \\
\hline ICC & 0.33 & 0.75 & 0.65 & 0.60 & 0.58 & 0.18 & 0.23 & 0.55 & 0.65 & 0.64 \\
\hline $\begin{array}{l}\text { LOA } \\
\left({ }^{\circ} \mathrm{C}\right) \\
(95 \% \\
\mathrm{CI})\end{array}$ & $\begin{array}{l}1.28 \\
(-0.54 \\
-2.03)\end{array}$ & $\begin{array}{l}1.05 \\
(-0.16 \\
-1.94)\end{array}$ & $\begin{array}{l}1.17 \\
(-0.13 \\
-2.20)\end{array}$ & $\begin{array}{l}1.01 \\
(-0.18 \\
-1.84)\end{array}$ & $\begin{array}{l}1.21 \\
(-0.36- \\
2.06)\end{array}$ & $\begin{array}{l}2.22 \\
(-0.11 \\
-4.34)\end{array}$ & $\begin{array}{l}1.10 \\
(0.72- \\
2.92)\end{array}$ & $\begin{array}{l}1.27 \\
(0.66- \\
3.19)\end{array}$ & $\begin{array}{l}1.28 \\
(0.58- \\
3.15)\end{array}$ & $\begin{array}{l}1.44 \\
(0.49- \\
3.38)\end{array}$ \\
\hline
\end{tabular}

From top to bottom; descriptive statistics, change in mean ( $\Delta$ mean), typical error of the estimate (TEE), intraclass correlation coefficient (ICC), limits of agreement (LOA). '*' denotes significant difference whereby $p<0.05,{ }^{\text {' }} \mathrm{CI}$ ' $=95 \%$ confidence interval.

\section{Vitae}

\section{Carl James}

Carl received his Masters degree in Sport and Exercise Science (Physiology) in 2012 and undergraduate degree in Sport Science in 2009. Carl began his $\mathrm{PhD}$ at the University of Brighton in 2012 which is examining short and long term strategies to mediate the decline in endurance running performance in hot and humid conditions. Carl recently presented at the 
inaugural Training and Competing in the Heat Conference in Qatar and is an active member of British Association of Sport and Exercise Science (BASES).

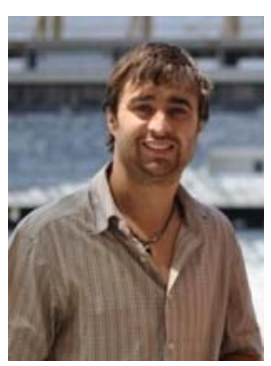

\section{Dr Alan Richardson}

Dr Alan Richardson's research focuses on the physiological changes and human tolerance to hypoxia and severe heat exposure. Dr Richardson worked as a research exercise physiologist on the Centre for Aviation, Space and Extreme Environment Medicine Xtreme Everest Project in 2007 and 2009, carrying out cardiopulmonary exercise testing in trekkers ascending to Everest Base Camp. Since then Dr Richardson has lead a research consultancy project with the National Fire Service investigating the immune function and inflammatory responses to repeated fire exposures in Fire Service instructors. Dr Richardson is continuing to investigate thermal interventions and post heat exposure cooling strategies.

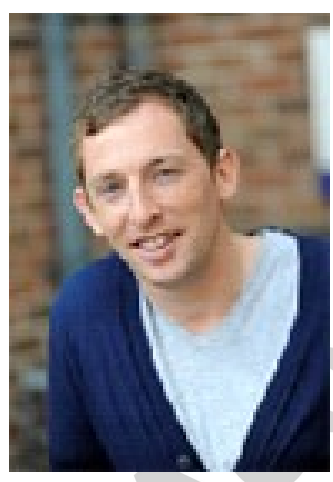

\section{Dr Peter Watt}

Dr Peter Watt has published over 90 peer reviewed articles, 90 abstracts and currently acts as a reviewer for multiple international journals. Dr Watt's research focuses on the application of stable isotope methods to measure metabolic and physiological changes occurring in humans during exercise, with application to health related problems, e.g. diabetes, obesity. Dr Watt has supervised $11 \mathrm{PhD}$ and $1 \mathrm{MPhil}$ completions and is currently supervising a further 5 PhD students. 


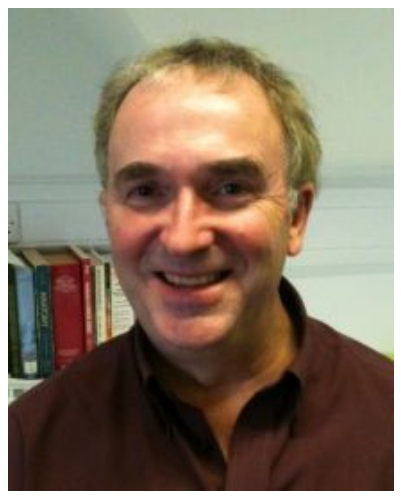

\section{Dr Neil Maxwell}

Dr Neil Maxwell joined the University of Brighton as a lecturer in sport and exercise science in 1997. Dr Maxwell continues to lecture undergraduate and postgraduate students, predominantly in the areas of exercise and environmental physiology and research methods. Dr Maxwell is research active and has published extensively in the international, scientific literature in areas allied to thermal and hypoxic stress and how the body tolerates each, particularly during exercise. $\mathrm{He}$ is an approved higher degrees supervisor with $\mathrm{MPhil} / \mathrm{PhD}$ completions, external examination experience and a bank of existing postgraduate research students.

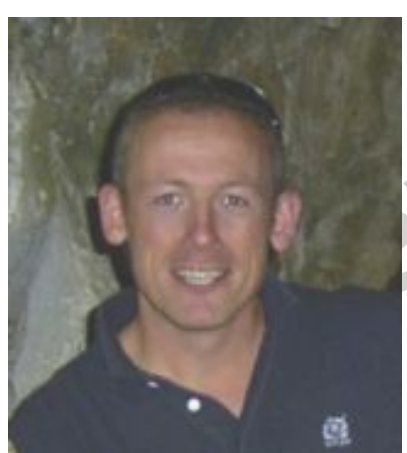




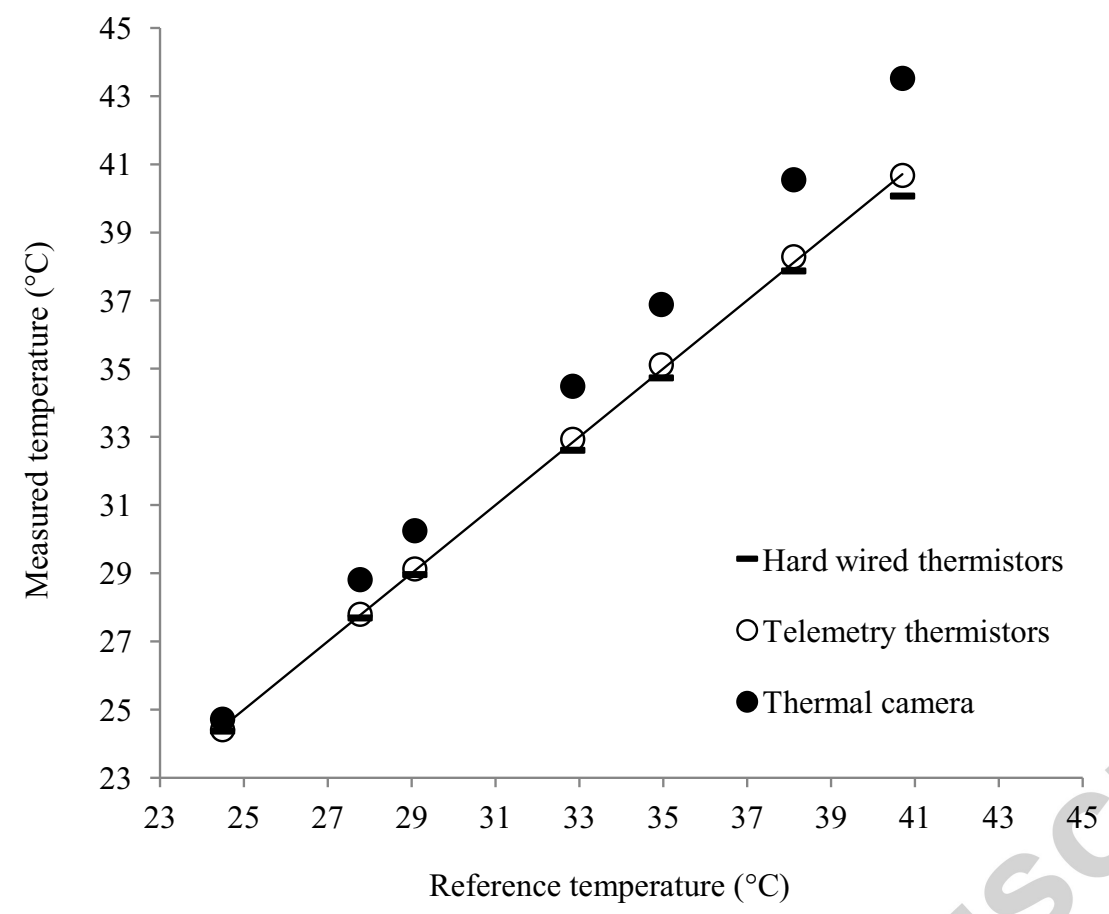

Figure 1 Mean uncorrected data from hard-wired, telemetry system and thermal camera during each waterbath plateau temperature across the range $25-40^{\circ} \mathrm{C}$. The dark line represents the criterion thermocouple (CT) against which thermistors and camera data was corrected. 


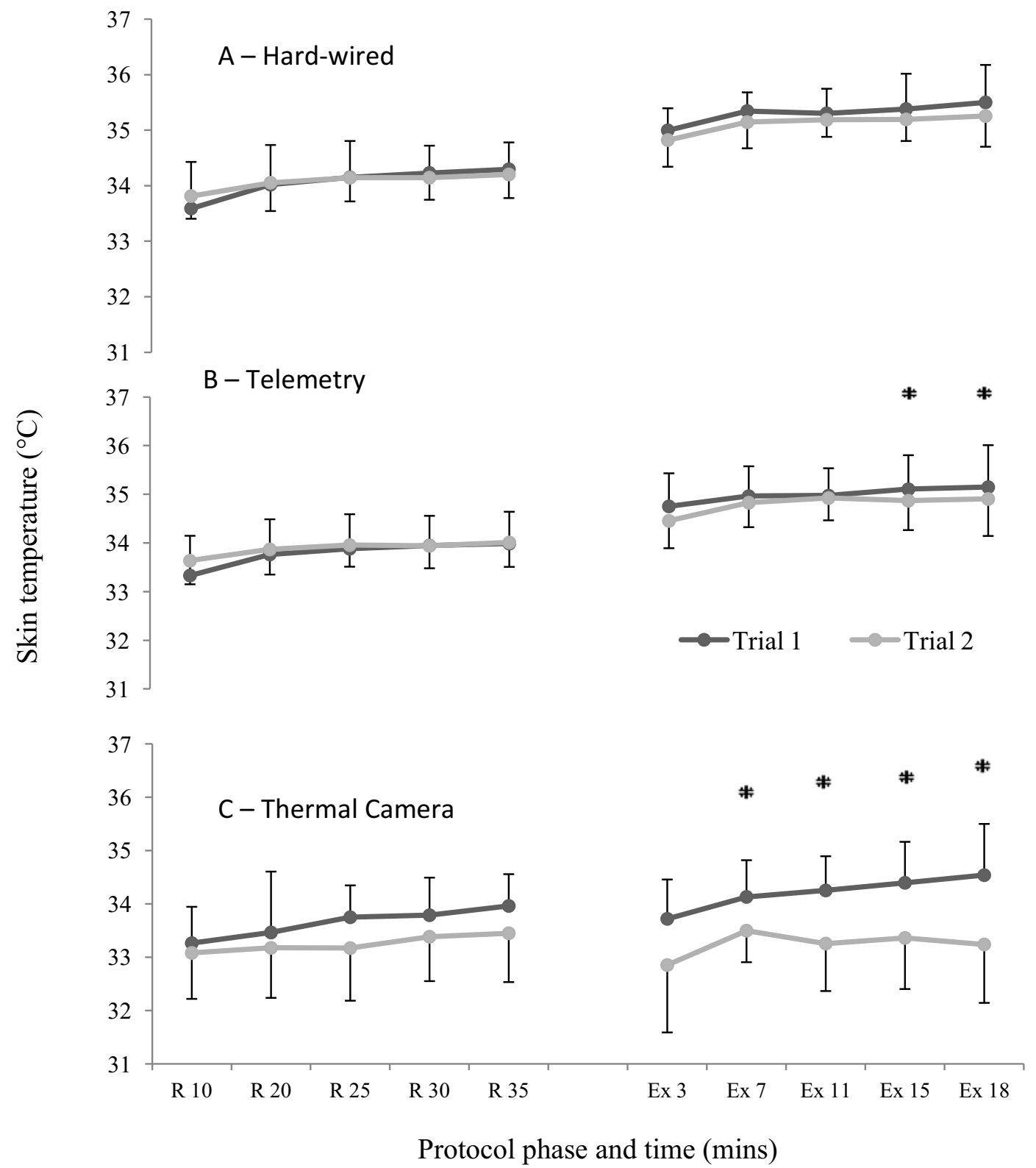

Figure 2: Mean (SD) reliability of wired thermistors, telemetry thermistors and thermal camera measuring skin temperature. ' $\mathrm{R}$ ' $=$ rest, 'Ex' $=$ exercise. ' $*$ ' denotes a difference between trials $(p<0.05)$. 